The innominate tubercle of the femur: application to anterior surgical approaches to the hip

Kielbasinski Podlaszewska $\mathrm{O}^{1}$, Bekvalac $\mathrm{J}^{2}$, Williams $\mathrm{RL}^{3}$, Adds $\mathrm{PJ}^{1}$

${ }^{1}$ Institute of Medical and Biomedical Education (Anatomy), St George's, University of London, London, UK.

${ }^{2}$ The Centre for Human Bioarchaeology, Musuem of London, London, UK

${ }^{3}$ Department of Trauma and Orthopaedics, Swansea Hospital, Swansea, UK

$\sqrt{2}$

Abbreviated title: The innominate tubercle: a survey of variability

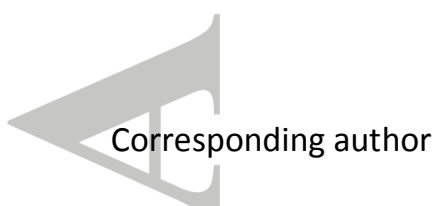

Philip J Adds, Institute of Medical and Biomedical Education (Anatomy), St George's, University of London, Cranmer Terrace, London SW17 ORE, UK. Email: padds@sgul.ac.uk, 02087255208

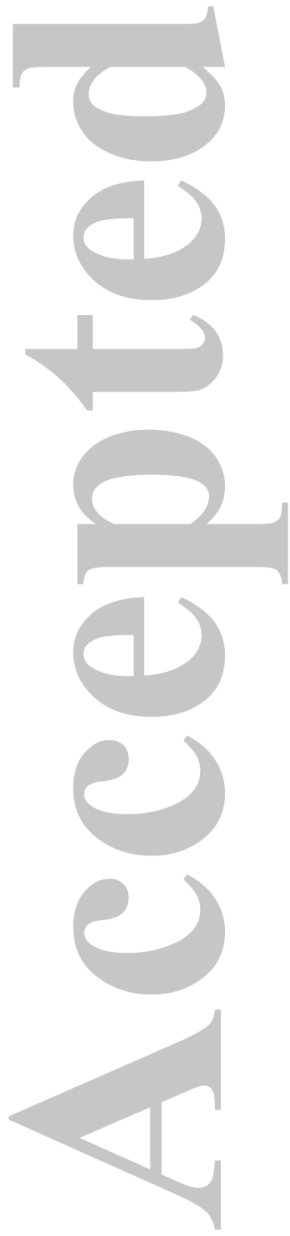

This article has been accepted for publication and undergone full peer review but has not been through the copyediting, typesetting, pagination and proofreading process which may lead to differences between this version and the Version of Record. Please cite this article as an 'Accepted Article', doi: 10.1002/ca.22870 


\section{The innominate tubercle of the femur: application to anterior surgical approaches to the}

hip

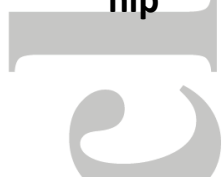

Abstract

Introduction. There has recently been an increase in popularity of the direct anterior approach (DAA) hip arthroplasty, due to the muscle sparing nature of its interneural intervals, with the innominate tubercle being used as a lateral reference point for the femoral neck osteotomy.

However, there is very little information in the literature on this rather enigmatic structure, with no evidence as to whether it is a consistent and reliable marker, or if it varies significantly in the population.

Materials and Methods. In this study, data were gathered from 79 pairs of adult, post-medieval skeletal femora to investigate the effects of sex, age, femoral side, femoral length, femoral neck length, and femoral neck-shaft angle on the width, length, and height of the innominate tubercle. The sex, age, and date of death of the individuals had been recorded. Statistical analysis included canonical correlation and multivariate multiple regression.

Results. We found that there was no statistical significance or correlation between the width, length, or height of the tubercle with respect to any of the variables investigated.

Conclusions. These results suggest that the innominate tubercle does not differ markedly between individuals in the Caucasian population, and, is therefore, a reliable landmark for femoral neck osteotomy during DAA hip arthroplasty. We present what we believe to be a definitive survey of the variability of the innominate tubercle in a Caucasian population.

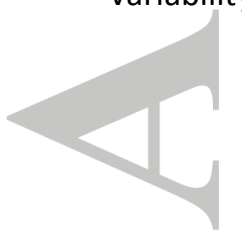


Keywords: arthroplasty; femur; femur neck; innominate tubercle; direct anterior approach; femoral osteotomy

\section{Introduction}

The earliest reference to the innominate tubercle that could be found in the literature described it thus: 'a prominence, of variable size, occurs at the junction of the upper part of the neck with the greater trochanter, and is called the tubercle of the femur' (Gray, 1918). Aside from the 'tubercle of the femur', this anatomical landmark has also been labelled as the 'cervical tubercle', 'superior cervical tubercle', 'femoral tubercle', 'innominate tubercle' and the 'third tubercle' (Frazer, 1920; Prasad et al., 1996; O'Rahilly et al., 2004; Field, 2015) (Fig. 1). It forms the distal site of attachment of the superior band of the iliofemoral ligament, sometimes termed the 'iliotrochanteric ligament'. There is currently not an official Terminologica Anatomica term for this structure; we suggest that "innominate tubercle" should be adopted, as it appears to have the widest currency in the literature. There are very few books, and even fewer studies, which mention this structure, despite its growing importance as a landmark for direct anterior approach (DAA) hip arthroplasty: Williams et al. (2015) describe the innominate tubercle as a "lighthouse" for making the femoral neck cut. The DAA procedure is a minimally invasive approach which enables the joint to be accessed by moving the muscles aside along natural planes of separation. Significantly, recovery time has been shown to be shorter, and with over 300, 000 primary total hip arthroplasties per year in the USA alone (Kurtz et al., 2014), the potential savings could be considerable. Williams et al. (2014) describe a study of a consecutive single-surgeon series of 151 patients using the innominate tubercle as a reference marker for femoral neck osteotomy during DAA hip arthroplasty. To assess the precision of the femoral neck osteotomy, discrepancy in lower limb length was used as a surrogate marker. Their results showed that the range of difference between limb lengths was -3 to $+3 \mathrm{~mm}$ with a mean of $1.7 \mathrm{~mm}$, suggesting that the tubercle can be used as a reliable intra-operative marker for femoral neck osteotomy. 


\section{Figure 1}

The only previous study that we were able to find in the literature (Prasad et al., 1996) investigated several prominences of the femur, including what they termed 'the superior cervical tubercle,' using 171 unpaired femora from Indian individuals assumed to be between 25 and 55 years of age. The femora were sexed by measuring the femoral heads. To determine the protuberance of the tubercle, the maximum width was measured, and then a score of 0-4 was assigned, where 0 signified that the tubercle was absent, and 4 = highly prominent. Their study was, however, limited by using unpaired femora from individuals whose age and sex were unknown, and therefore had to be estimated.

The aim of the work reported here was to improve on the study of Prasad et al. (1996) by using paired femora, from individuals with known biographical data; hence, age at death, sex and date of death were known. Using paired femora permitted analysis of possible left/right variation due, for example, to limb dominance. We investigated the variability of the innominate tubercle in an archaeological skeletal population dating from between the $18^{\text {th }}$ to the mid-19 $19^{\text {th }}$ century, located at St. Bride's Church, London, UK. Tubercle dimensions were analysed in relation to femoral side, sex, age, femoral length, femoral neck length, and femoral neck-shaft angle. Since there is so little information on the tubercle in the literature, we aimed to provide a definitive description of the morphology of the innominate tubercle, and to establish whether the size and shape are affected by any of the aforementioned variables. It is hoped that the data presented here can be used to inform future DAA surgeries. Femoral osteotomy can vary considerably between individuals and therefore a surgeon needs to be confident that the landmark used during surgery is a reliable and dependable guide. The comprehensive survey of innominate tubercle variability presented here may also be of interest to research osteologists and forensic anthropologists.

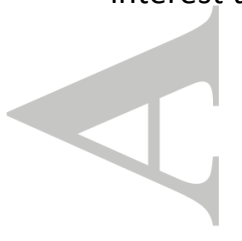




\section{Materials and Methods}

The crypt of St Bride's Church, London, U.K., contains 227 well-preserved skeletons dating from between 1673-1853. These individuals had been buried in lead-lined coffins, complete with name plates giving the age, date of birth and date of death. The lead lining of the coffin decelerated the process of decomposition and gave protection from environmental factors that could cause taphonomic degradation, which, together with the associated biographical data, makes this assemblage a very valuable resource for research (Bekvalac, 2012). Of the 227 skeletons available, 79 femoral pairs were undamaged and viable; the remainder were excluded from the investigation. Exclusion criteria included: fracture or incompleteness of the femur, gross deformity including rickets, gross damage to either end of the bone, and damage to the tubercle in either of the paired femora. Name, age and date of death for each individual had been recorded from the coffin plates.

\section{Measurements}

To eliminate the possibility of inter-observer variability, all measurements in this study were made by the same operator. All measurements were repeated three times, and the mean calculated. The maximum femoral length was defined as the straight line distance between the most superior point on the femoral head and the most distal point of the medial condyle (Pillai et al., 2014). An osteometric board was used to measure the length, the femur being placed horizontally with the anterior side facing upwards, ensuring that the femoral shaft was lying straight along the centre of the board. Femoral length was recorded to the nearest $1 \mathrm{~mm}$.

Femoral neck-shaft angle is described as 'the angle formed by the neck axis and the femoral-shaft axis' (Arnold et al., 1997). This was measured with a steel goniometer, making sure that the midline of the goniometer arms was lined up with the axis of the neck and shaft respectively (Fig. 2). 
Osorio et al. (2012) refers to femoral neck length as the measurement from the intertrochanteric line to the inferior region of the femoral head. However, several of the femora had a cortical bone defect on the inferior aspect of the femoral heads, due either to post-mortem damage or the presence of Allen's fossa (White et al., 2012). Therefore, the femoral neck length was measured at the mid-point of the femoral neck, from the medial border of the intertrochanteric line to the epiphyseal line, which was always clearly visible (Fig. 2). Since the area of damage was small in these cases it was not considered necessary to exclude these femora from the study. Measurements were taken with digital callipers, accurate to $0.01 \mathrm{~mm}$.

Figure 2

The length and breadth of the tubercle were measured with the digital callipers, by placing the calliper jaws at the superior and inferior borders, and medial and lateral borders of the tubercle, respectively.

A contour gauge with a small pin size was used to measure the height of the tubercle. The femur was placed on the bench with the femoral neck parallel with the plane of the bench. The gauge was then pressed on to the tubercle, perpendicular to the long axis, so that a transverse impression was obtained (Fig. 3). The height of the impression was then measured with the digital callipers. After each measurement the contour gauge was reset by re-aligning the pins on a flat surface.

Figure 3

Intra-rater reliability test

To assess operator reliability, the measurements on one randomly chosen femur were repeated three times on seven separate occasions. The coefficient of variance was then calculated. 


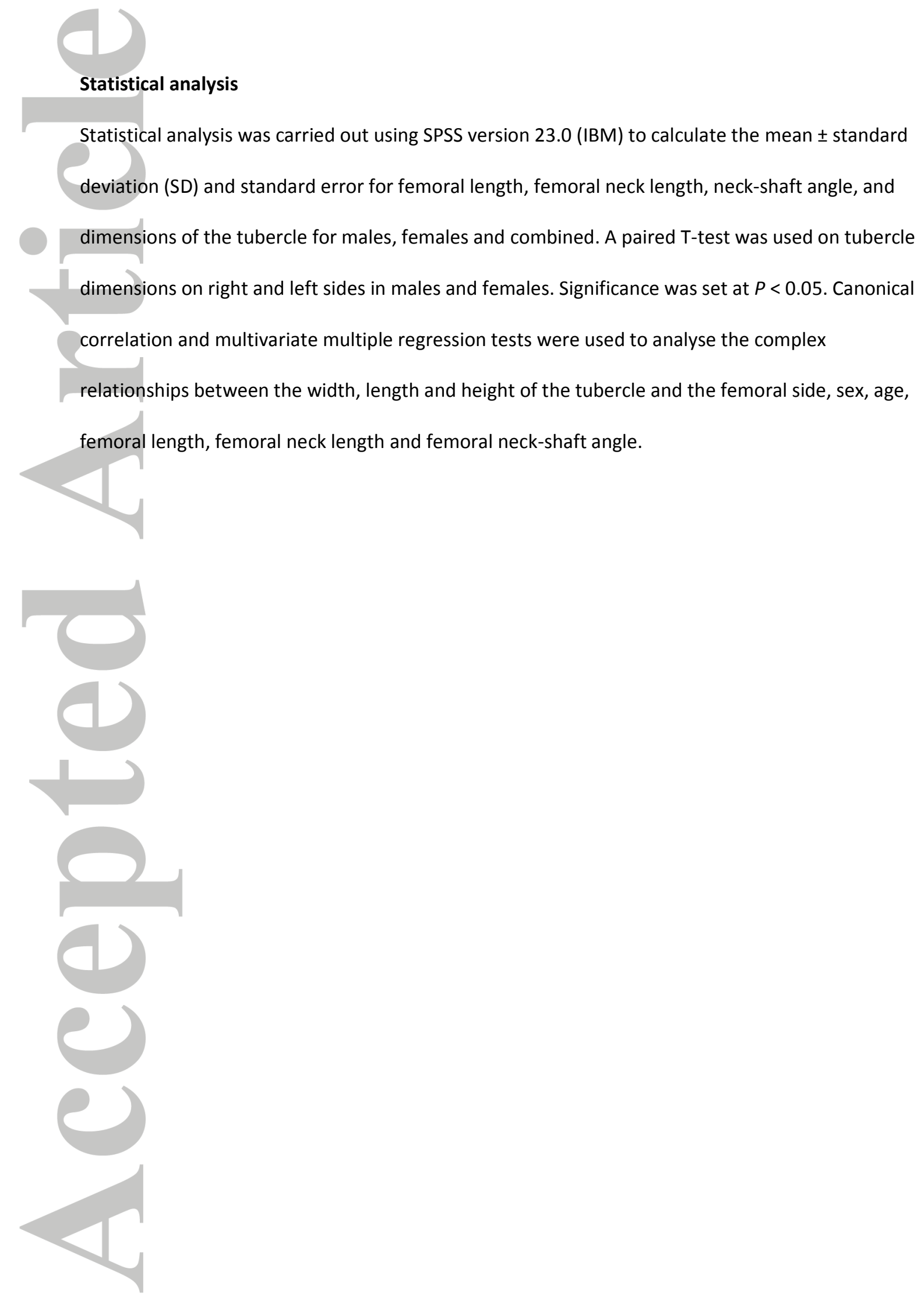

John Wiley and Sons, Inc.

This article is protected by copyright. All rights reserved. 


\section{Results}

Out of the 227 skeletons at St. Bride's, 79 were in a suitable condition to be measured: 35 males and 44 females, aged from 18 to 91 years, with a mean age of 54.5 years (male) and 54.3 (female) (Table 1).

Table 1

Tables 2-4 show the mean, SD, and standard error for males, females, and both combined. Although males had a higher mean in all variables on both sides, this was found to be not statistically significant $(P>0.05)$. The mean right tubercle width was $9.77 \pm 0.25 \mathrm{~mm}$, and the mean left width was $9.81 \pm 0.23 \mathrm{~mm}$. Females had a larger range in left width and length of tubercle. Males had a larger range of both right and left tubercle heights, $3.66 \mathrm{~mm}$ for the right side and $3.96 \mathrm{~mm}$ for the left, compared to $3.46 \mathrm{~mm}$ and $2.77 \mathrm{~mm}$ respectively in the females.

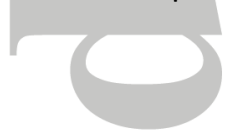

Tables 2-4

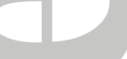

The correlation coefficient, $r$, of the variables was calculated and compared against right and left sides, and sex. All values were found to be insignificant $(P>0.05)$, with very weak to no association between the variables in question. Values ranged from -0.245 to 0.269 for males, and from -0.273 to 0.305 for females. The coefficient of determination, $r^{2}$, was also calculated (Figs 5, 6).

Figure 5

Figure 6

Statistical analysis

Canonical correlation and multivariate multiple regression statistical tests were carried out on the data. It was found that there was no statistical association between the width, length and height of

John Wiley and Sons, Inc.

This article is protected by copyright. All rights reserved. 
the innominate tubercle compared to femoral side, sex, age, femoral length, femoral neck length or femoral neck-shaft angle.

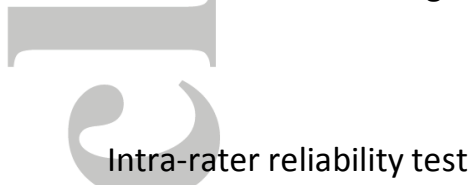

The mean, variance, SD and coefficient of variation for measurements taken on seven separate occasions were calculated. The SD for femoral length, femoral neck length and tubercle size ranged from $0.00-0.29$. Standard deviation of the femoral neck-shaft angle was slightly higher at 1.18 and 1.05 on the right and left respectively. The coefficient of variation ranged from $0.0 \%-2.7 \%$ for all parameters except tubercle height, indicating a very high degree of operator reliability. It was noticeably higher in the tubercle height measurements (8.12\% [right] and 3.98\% [left]), indicating the more subjective nature of the assessment of tubercle height.

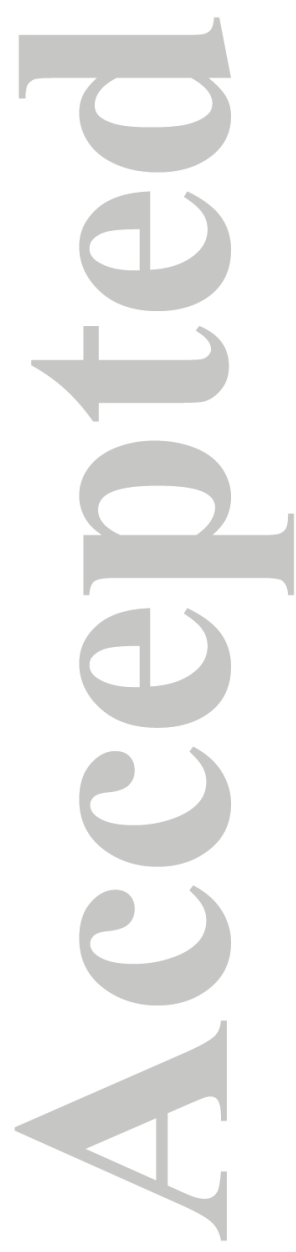

John Wiley and Sons, Inc.

This article is protected by copyright. All rights reserved. 


\section{Discussion}

The results of this study present a detailed analysis of the variation of the innominate tubercle of the femur. There is little information about this structure in the literature, and even its name is undecided. "Innominate" may indeed be the mot juste. The presence of this structure has recently assumed a greater significance, however, because of its role as a landmark for femoral osteotomy during DAA hip arthroplasty. The paucity of information about this structure in the literature led the authors to undertake this study to endeavour to fill what we perceived as a gap in general awareness of this structure's existence and its variation in the population. In terms of discussing how our findings relate to previous studies, this presents a problem, as the only other comparable study the authors could find was that of Prasad et al. (1996). We have, therefore, largely discussed our findings with two considerations in mind: their relevance to DAA hip arthroplasty, and their similarities or differences to Prasad et al.'s results.

Femoral side

The results reported here support Prasad et al.'s (1996) finding that prominence of the tubercle does not vary significantly between right and left sides. While Prasad et al. used unpaired femora, the paired femora in this study enabled comparison of left to right measurements in a single individual. It might be expected to see more muscle attachment, and hence a larger tubercle, on the dominant limb, as has been seen for example, in the skeletons of the Mary Rose archers (Knüsel, 2010). It is, however, possible that dominance is randomly distributed in the lower limb, or that the upper limb is more predisposed to this effect than the lower limb, especially in activities like archery, where there is a markedly unequal division of labour between left and right limbs. Such a discrepancy is difficult to envisage in the lower limbs of the sample population investigated here.

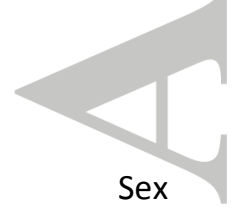


This study found no evidence to support Prasad et al.'s (1996) finding that males had a more prominent tubercle. Although it might be intuitively supposed that men, being generally larger, heavier and stronger, would have correspondingly larger bones with more pronounced surface markings, there was no evidence of this in the sample we analysed for this study. Locating the tubercle intra-operatively in female patients should not, therefore, present any more of a challenge than in male patients. An important difference between the sample in our study compared to Prasad et al.'s is that the sex of the skeletons was known; having to establish the sex from analysis of the femoral heads (a method of uncertain accuracy) may have introduced an unconscious element of self-selection, whereby femora with more pronounced bony protuberances may have been assumed to be male.

Age

The anterior intertrochanteric line can differ widely in development, appearing to become more pronounced with age (Pope et al., 2015). As the intertrochanteric line terminates with the innominate tubercle at its most superolateral border, it might be expected that the tubercle would follow this pattern. However, canonical correlation and multivariate multiple regression tests showed no statistical association between age and size (length, width, and height) of the tubercle in the adult skeleton. Prasad et al. (1996) were unable to correlate their measurements with the age of the subject since it is not possible accurately to age individual femora. While the functional significance of this finding may be uncertain, it does suggest that the tubercle is a relatively constant feature throughout life, making it a dependable landmark for surgery irrespective of age.

Femoral length, neck length, and neck-shaft angle

No statistical association was found between femoral length, femoral neck length, femoral neckshaft angle, and the size of the tubercle. In a study of over 8000 femora, Gilligan et al. (2013) found a 
world-wide mean neck-shaft angle of $127^{\circ}$, with no sex or age-related differences. The overall combined average reported here $\left(128.5^{\circ}\right)$ is higher than the $125.5^{\circ}$ reported for England, but this may be accounted for by the reported trend for an increase in NSA to accompany a move towards urbanisation, since the population investigated here were all from London (Gilligan et al., 2013).

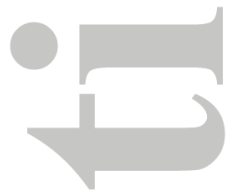

\section{Conclusion}

In contrast to Prasad et al.'s (1996) study, the innominate tubercle was found to have no significant association between prominence and sex. Neither length, width, nor height of the tubercle had significant variation in males or females. However, the data support Prasad et al.'s (1996) conclusion that there was no significant association between prominence and sidedness.

Analysis of the data revealed no statistical association between age, femoral length, femoral neck length and femoral neck-shaft angle and the dimensions (length, width and height) of the innominate tubercle. This report is the first to have investigated these variables in comparison to the tubercle. We present here what we believe to be a definitive survey of the variability of the innominate tubercle in relation to sex, side, femoral length, femoral neck length and femoral neckshaft angle in a Caucasian population. The lack of any statistically significant associated variability in the size of the tubercle suggests that it may be used with confidence as a reliable and dependable landmark in orthopaedic surgery, unaffected by any of the above variables. Work is now ongoing to strengthen this study by establishing if there is variation in the position of the tubercle with respect to the femoral neck.

\section{Limitations}

This investigation was based on the analysis of $7918^{\text {th }}-19^{\text {th }}$ century skeletons. Although the skeletons are unusually well-preserved, there is the possibility that they may have been affected by the burial environment and taphonomic processes. It is also inevitable that these individuals would have had 
quite different lifestyles to a modern-day population, which may have had an effect on their skeletal morphology. Extrapolation of these results to the present day, therefore, should be treated with a degree of caution. Further investigations could be extended to a larger skeletal population including different ethnic groups. The most effective way of doing this may be to use imaging studies rather than using skeletal material due to the lack of recorded data regarding age, sex and ethnicity in most skeletal assemblages.

r

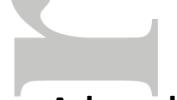

Acknowledgements

The authors gratefully acknowledge the assistance of the staff of St Bride's Church, Fleet Street, London.

The authors have no conflicts of interest to declare.

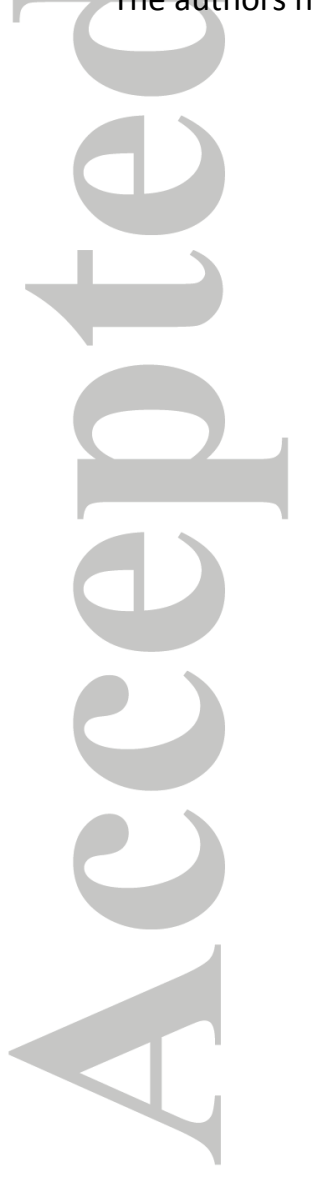

John Wiley and Sons, Inc.

This article is protected by copyright. All rights reserved. 


\section{References}

Arnold A, Komallu A, Delp S. 1997. Internal rotation gait: a compensatory mechanism to restore abduction capacity decreased by bone deformity? Dev Med Child Neurol 39: 40-44.

Bekvalac J. 2012. Implementation of preliminary digital radiographic examination in the confines of the crypt of St Bride's Church, Fleet Street, London. Proceedings of the Twelfth Annual Conference of the British Association for Biological Anthropology and Osteoarchaeology. Oxford: Archaeopress. pp 111-113.

Field R. 2015. Personal communication.

Frazer J. 1920. The Anatomy of the Human Skeleton. 2nd Ed. London: J and A Churchill. pp 138-140. Available at: https://archive.org/stream/anatomyofhumansk00frazuoft\#page/n205/mode/2up [Accessed 12 Feb. 2017].

Gilligan I, Chandraphak S, Mahakkanukrauh P. 2013. Femoral neck-shaft angle in humans: variation relating to climate, clothing, lifestyle, sex, age and side. J Anat 223: 1469-7580.

Gray H. 1918. Anatomy of the Human Body. 20th Ed. Philadelphia: Lea and Febiger. pp 244-245.

Knüsel C. 2010. Bone adaptation and its relationship to physical activity in the past. In: M. Cox and S Mays. (Eds.) Human Osteology: In Archaeology and Forensic Science, 1st Ed. New York: Cambridge University Press. pp 381-387.

Kurtz SM, Ong KL, Lau E, Bozic KJ. 2014. Impact of the economic downturn on total joint replacement demand in the United States: updated projections to 2021. J Bone Joint Surg (Am) 96: 624-630.

Osorio H, Schorwer K, Coronado C, Delgado J, Aravena P. 2012. Proximal femoral epiphysis anatomy in Chilean population: orthopedic and forensic aspects. Int J Morphol 30: 258-262. 
O'Rahilly R, Müller F, Carpenter S, Swenson R. 2004. Fig. 12-10 The right femur, anterior view, anatomical position. [Image] Available at:

http://www.dartmouth.edu/ humananatomy/figures/chapter_12/12-10.HTM [Accessed 12 Feb.

2017].

Pillai T, Lakshmi Devi C, Devi T. 2014. Osteometric studies on human femurs. IOSR-JDMS 13: 34-39.

Pope T, Bloem H, Beltran J, Morrison W, Wilson D. 2015. Musculoskeletal Imaging. 2nd Ed.

Philadelphia: Elsevier Health Sciences. p 284.

Prasad, R., Vettivel, S., Isaac, B., Jeyaseelan, L. and Chandi, G. (1996). Angle of Torsion of the Femur and its Correlates. Clin Anat 9, 109-117.

White T, Black M, Folkens P. 2012. Human Osteology $3^{\text {rd }}$ Ed. San Diego: Academic Press. p 252.

Williams R, Goodson M, Maheson M. 2014. The innominate tubercle and superimposition of the rasp - an accurate technique for the femoral neck osteotomy during the direct anterior approach to the hip. [Poster Presentation] European Hip Society, Stockholm.

Williams R, Goodson M, Danayana K, Maheson M. 2015. The innominate tubercle - a lighthouse for the femoral neck cut. Clin Anat 28: 419

John Wiley and Sons, Inc.

This article is protected by copyright. All rights reserved. 


\section{Figure Legends}

Figure 1. The innominate tubercle of the femur (arrow)

Figure 2. Measurement of femoral neck-shaft angle $\left({ }^{*}\right)$ and femoral neck length (arrow). The dotted line represents the intertrochanteric line.

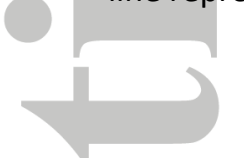

Figure 3. The height of the tubercle (arrow) was measured with a pin gauge.

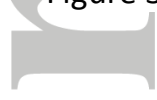

Figure 4A, B. Graphs showing femoral length in comparison to tubercle prominence for males (A)

and females (B).

Figure 5A, B. Graphs showing neck-shaft angle in comparison to tubercle prominence for males (A) and females (B).

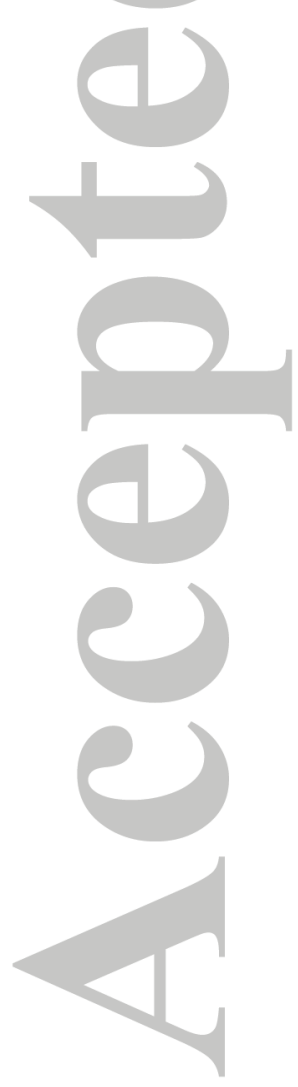

John Wiley and Sons, Inc.

This article is protected by copyright. All rights reserved. 

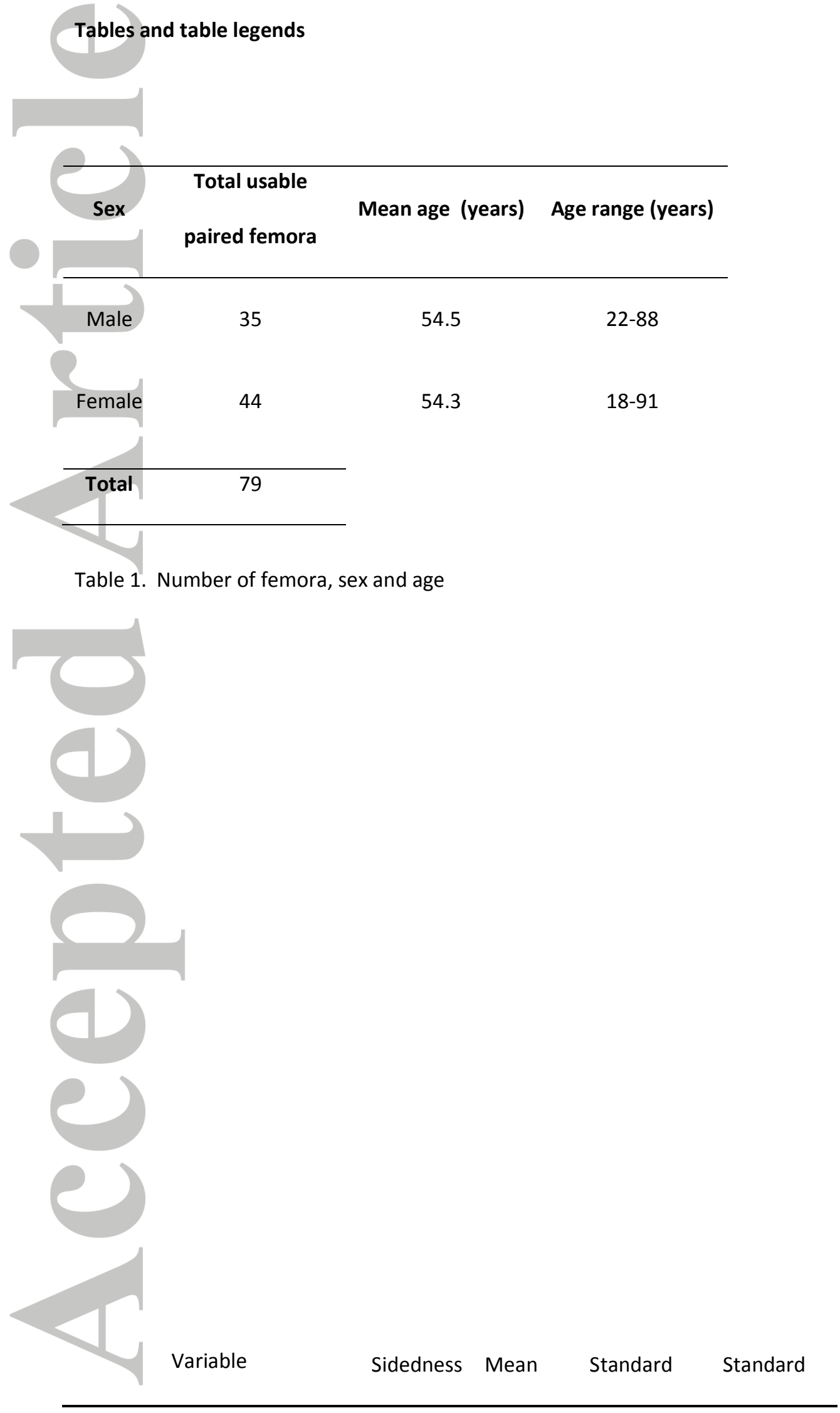

John Wiley and Sons, Inc.

This article is protected by copyright. All rights reserved. 


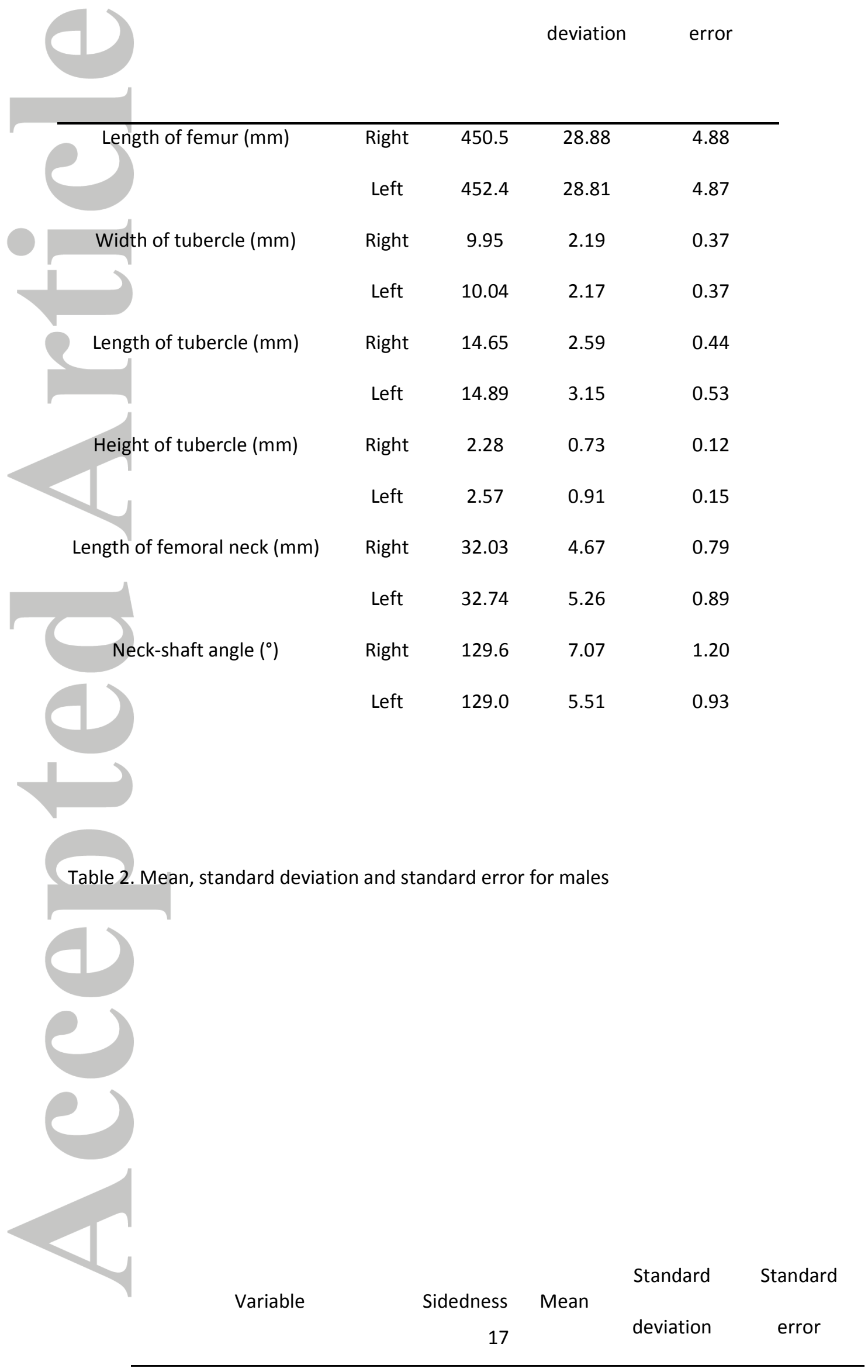

John Wiley and Sons, Inc.

This article is protected by copyright. All rights reserved. 


\begin{tabular}{|c|c|c|c|c|c|}
\hline \multirow{4}{*}{ 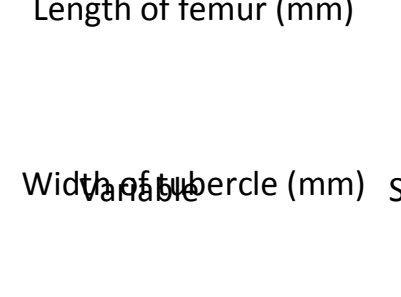 } & Right & 414.4 & 22.31 & & 3.36 \\
\hline & Left & \multicolumn{3}{|c|}{ 414.4 Standaza.34standard } & 3.37 \\
\hline & SidednRigght & \multicolumn{2}{|c|}{ Mea月.62 deviatißn19 } & \multirow[t]{2}{*}{ error } & 0.33 \\
\hline & Left & 9.64 & 2.02 & & 0.30 \\
\hline 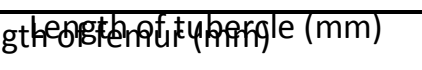 & RighRight & 430.44 .31 & $31.05^{2.67}$ & 3.49 & 0.40 \\
\hline & Left & 14.23 & 3.49 & & 0.53 \\
\hline Height of tubercle (mm) & Right & 1.98 & 0.72 & & 0.11 \\
\hline & Left & 2.55 & 0.71 & & 0.11 \\
\hline Length of femoral neck $(\mathrm{mm})$ & Right & 27.99 & 3.92 & & 0.59 \\
\hline & Left & 29.23 & 3.87 & & 0.58 \\
\hline Neck-shaft angle $\left({ }^{\circ}\right)$ & Right & 128 & 5.22 & & 0.79 \\
\hline & Left & 127.8 & 5.68 & & 0.86 \\
\hline
\end{tabular}

Table 3: Mean, standard deviation and standard error for females.

John Wiley and Sons, Inc.

This article is protected by copyright. All rights reserved. 


\begin{tabular}{|ccccc}
\hline Lidth of tubercle $(\mathrm{mm})$ & Right & 9.77 & 2.18 & 0.25 \\
& Left & 9.81 & 2.08 & 0.23 \\
\hline Length of tubercle $(\mathrm{mm})$ & Right & 14.46 & 2.62 & 0.29 \\
\hline Leight of tubercle $(\mathrm{mm})$ & Left & 14.52 & 3.34 & 0.38 \\
\hline Length of femoral neck $(\mathrm{mm})$ & Right & 2.11 & 0.74 & 0.08 \\
\hline Neck-shaft angle $\left({ }^{\circ}\right)$ & Left & 2.56 & 0.80 & 0.09 \\
& Light & 29.78 & 4.70 & 0.53 \\
\hline & Right & 128.7 & 6.12 & 0.69 \\
\hline & Left & 128.3 & 5.60 & 0.63
\end{tabular}

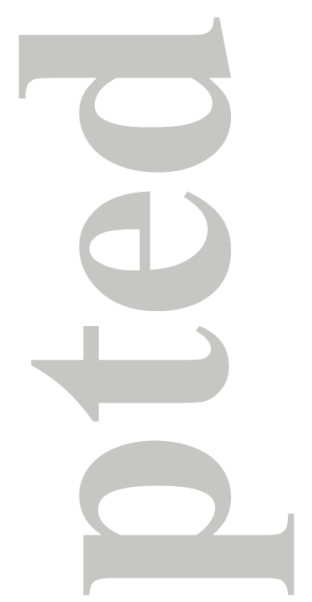

Table 4. Mean, standard deviation and standard error for males and females combined.
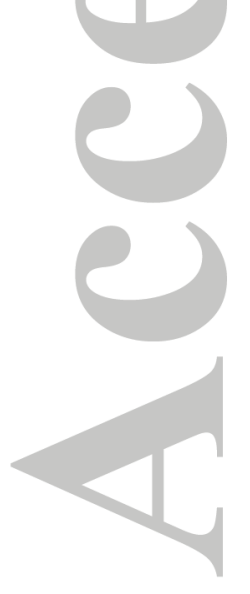

John Wiley and Sons, Inc.

This article is protected by copyright. All rights reserved. 


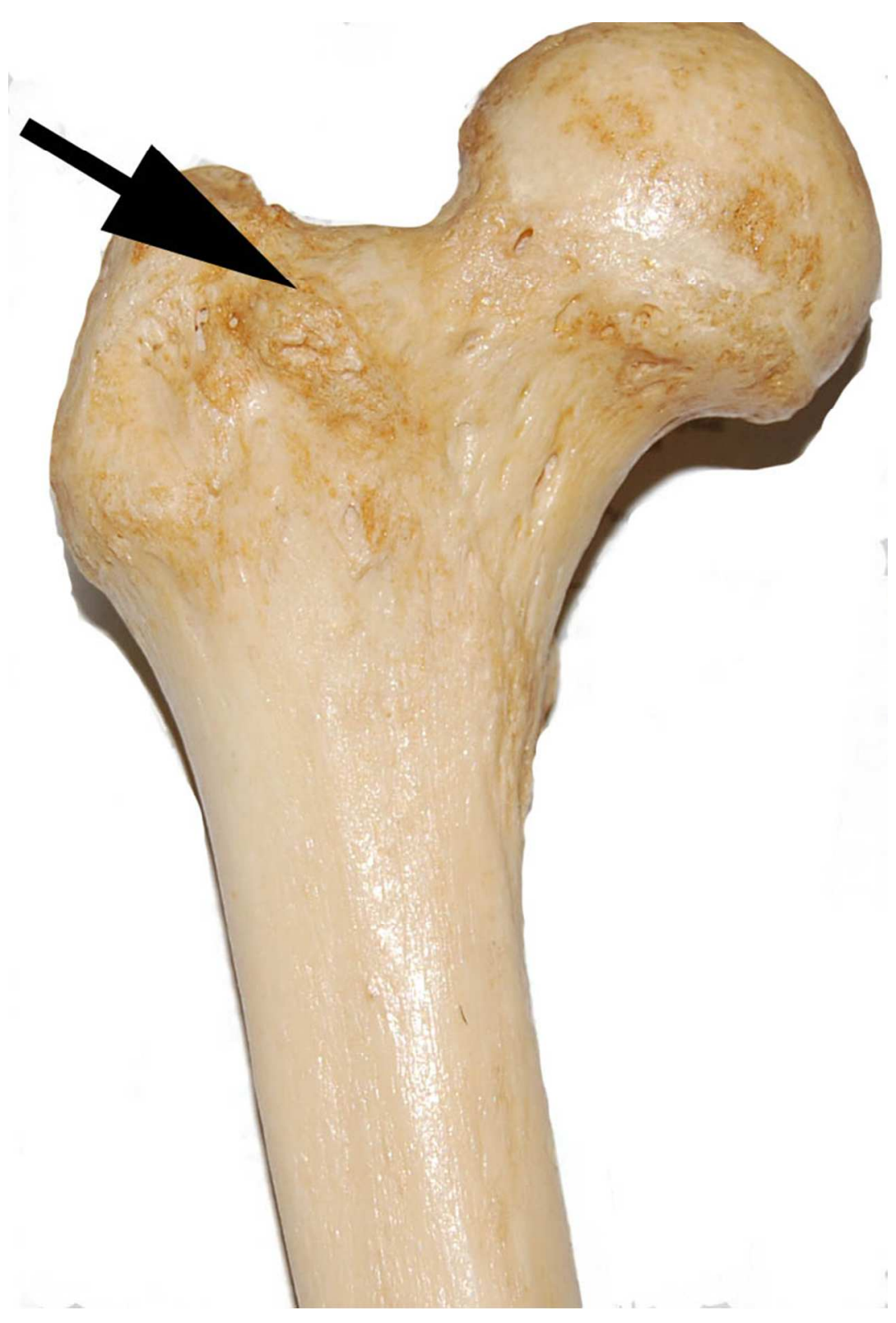

Figure 1. The innominate tubercle of the femur (arrow) $67 \times 98 \mathrm{~mm}(300 \times 300$ DPI $)$

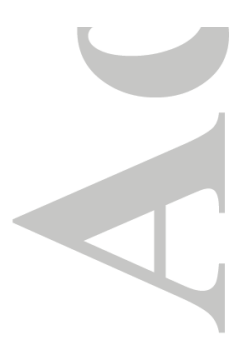

John Wiley and Sons, Inc.

This article is protected by copyright. All rights reserved. 


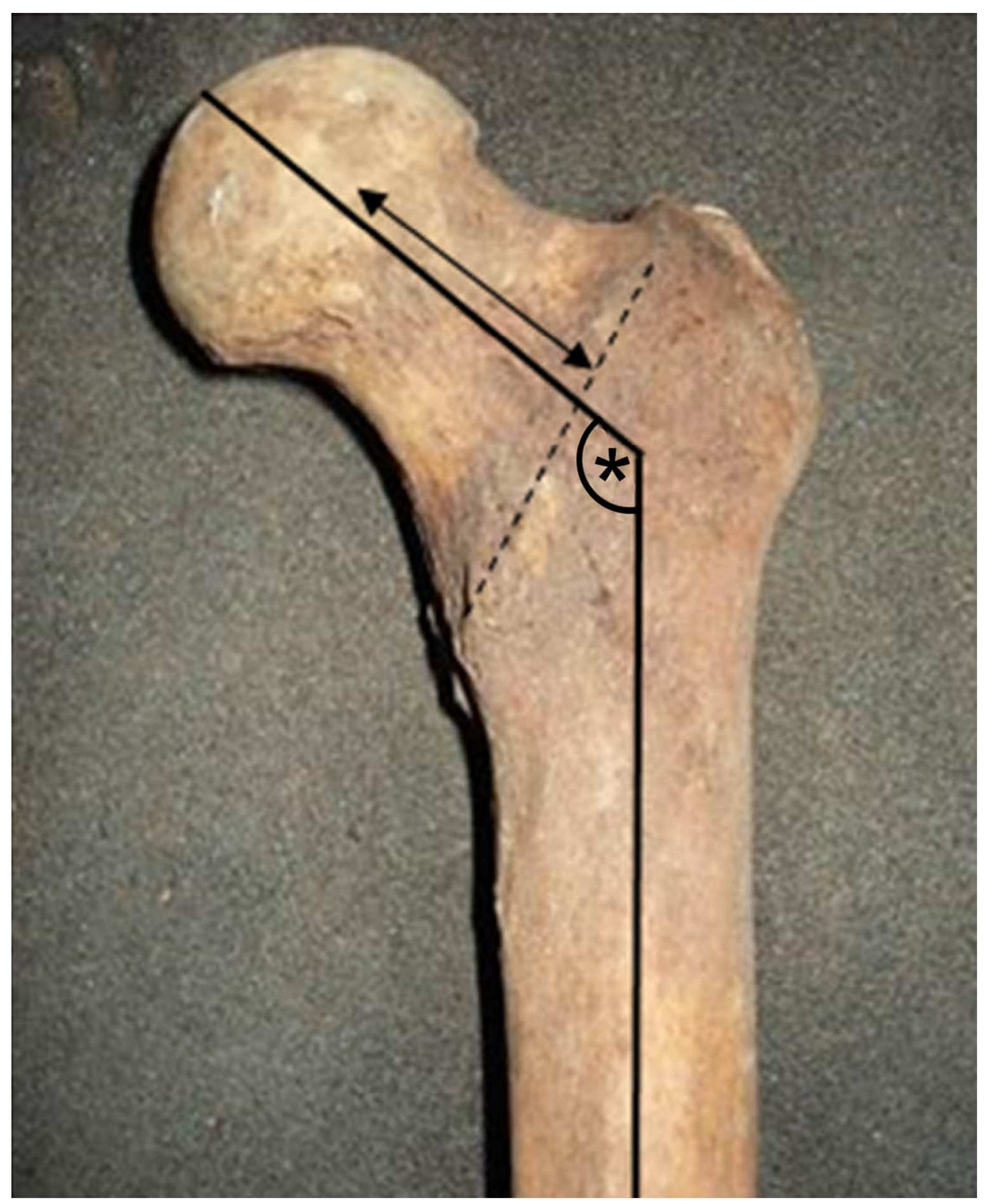

Figure 2. Measurement of femoral neck-shaft angle $(*)$ and femoral neck length (arrow). The dotted line represents the intertrochanteric line.

$93 \times 114 \mathrm{~mm}(300 \times 300 \mathrm{DPI})$

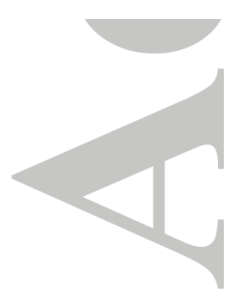

John Wiley and Sons, Inc.

This article is protected by copyright. All rights reserved. 


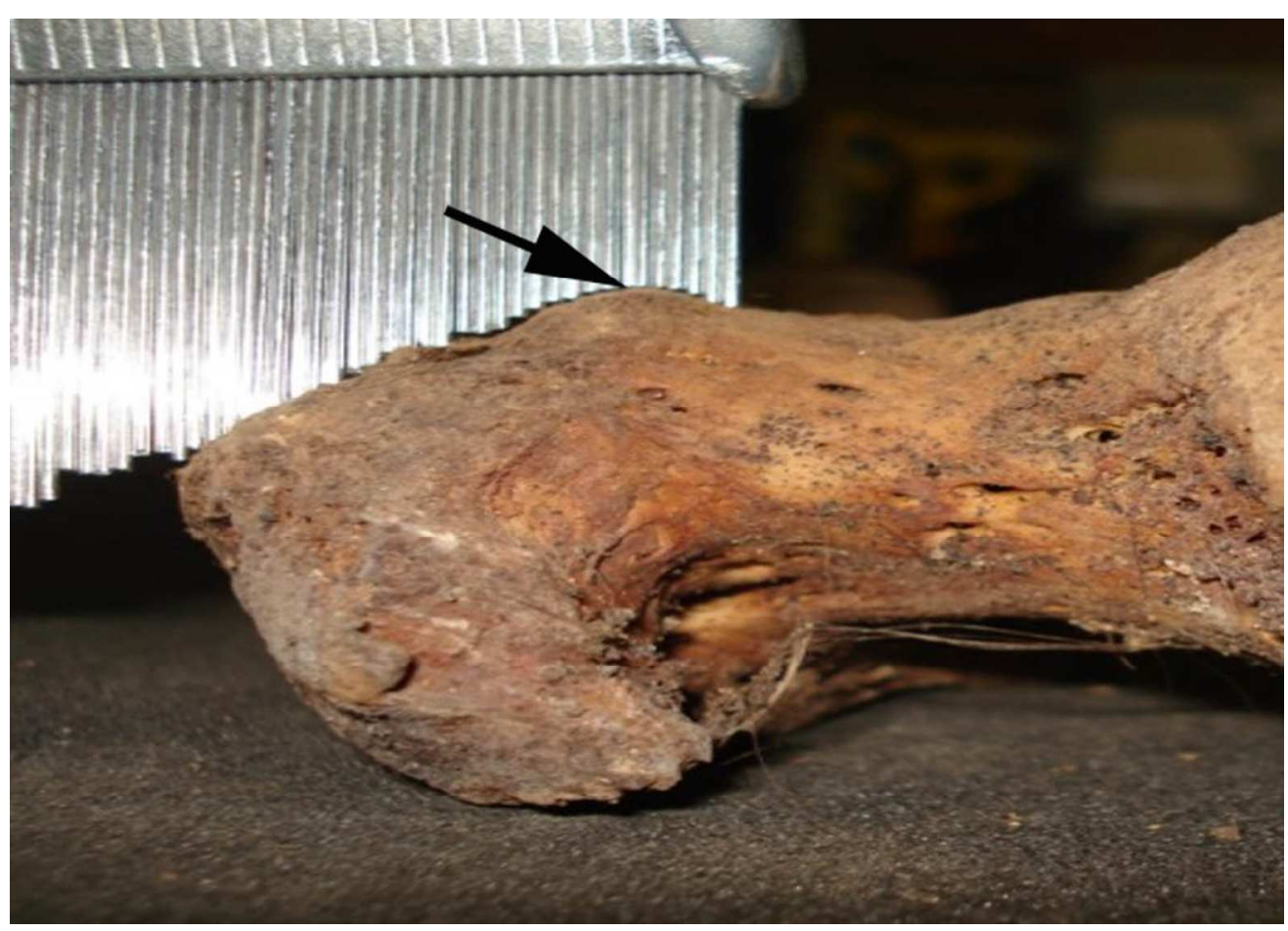

Figure 3. The height of the tubercle (arrow) was measured with a pin gauge. $232 \times 165 \mathrm{~mm}(150 \times 150 \mathrm{DPI})$

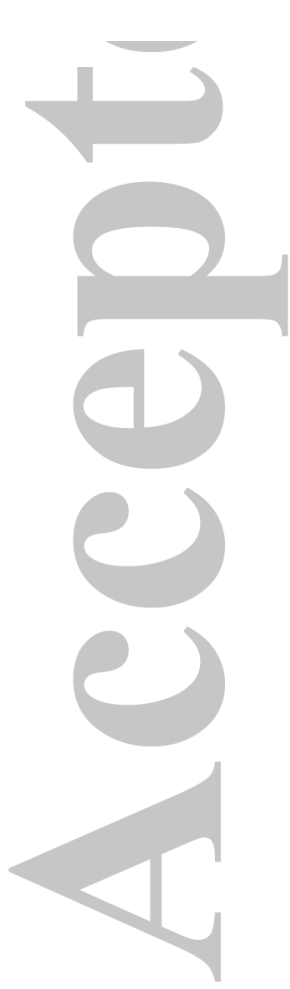

John Wiley and Sons, Inc.

This article is protected by copyright. All rights reserved. 

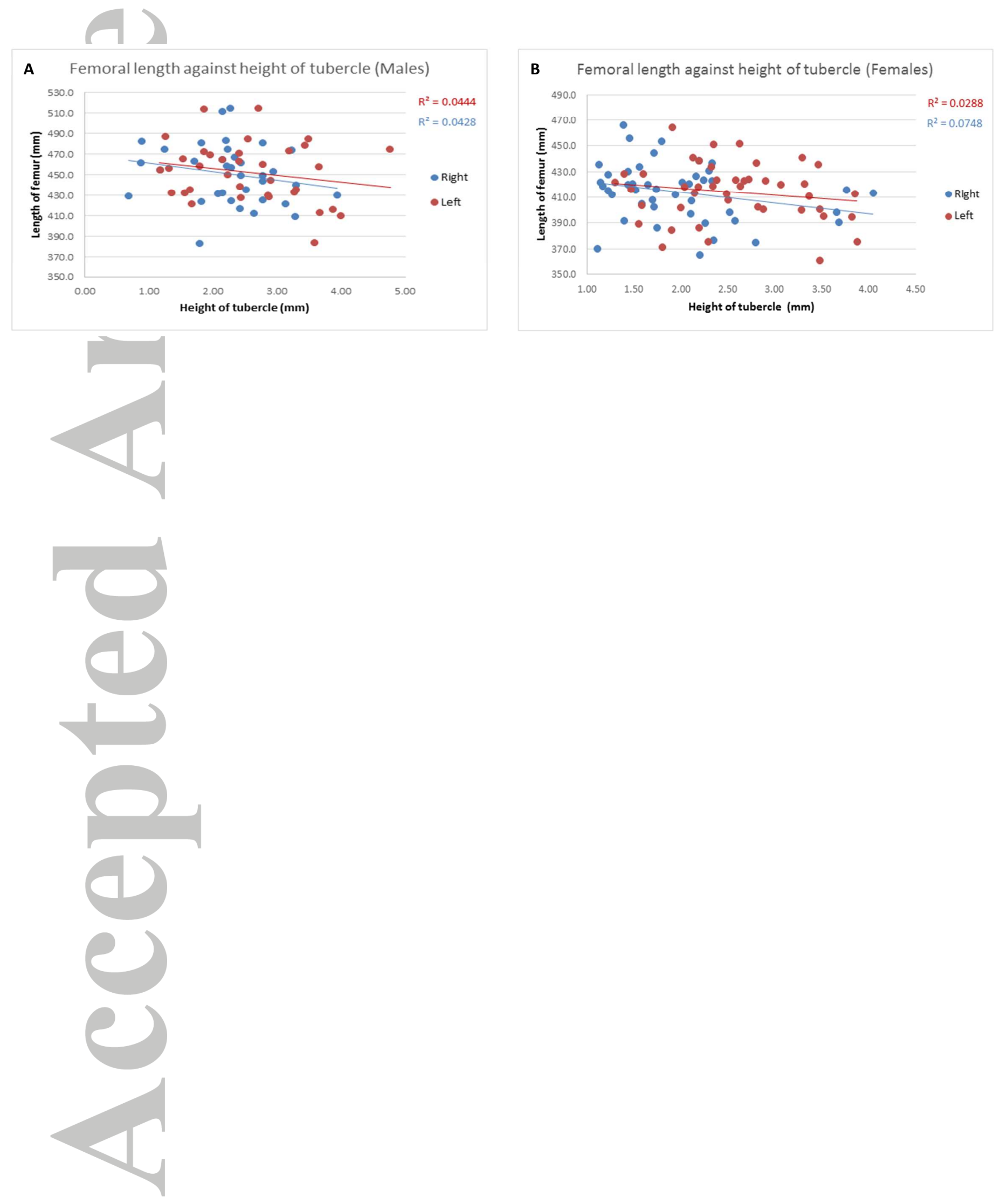

John Wiley and Sons, Inc.

This article is protected by copyright. All rights reserved. 


\section{(1)}

A Neck-shaft angle against height of tubercle (Males)
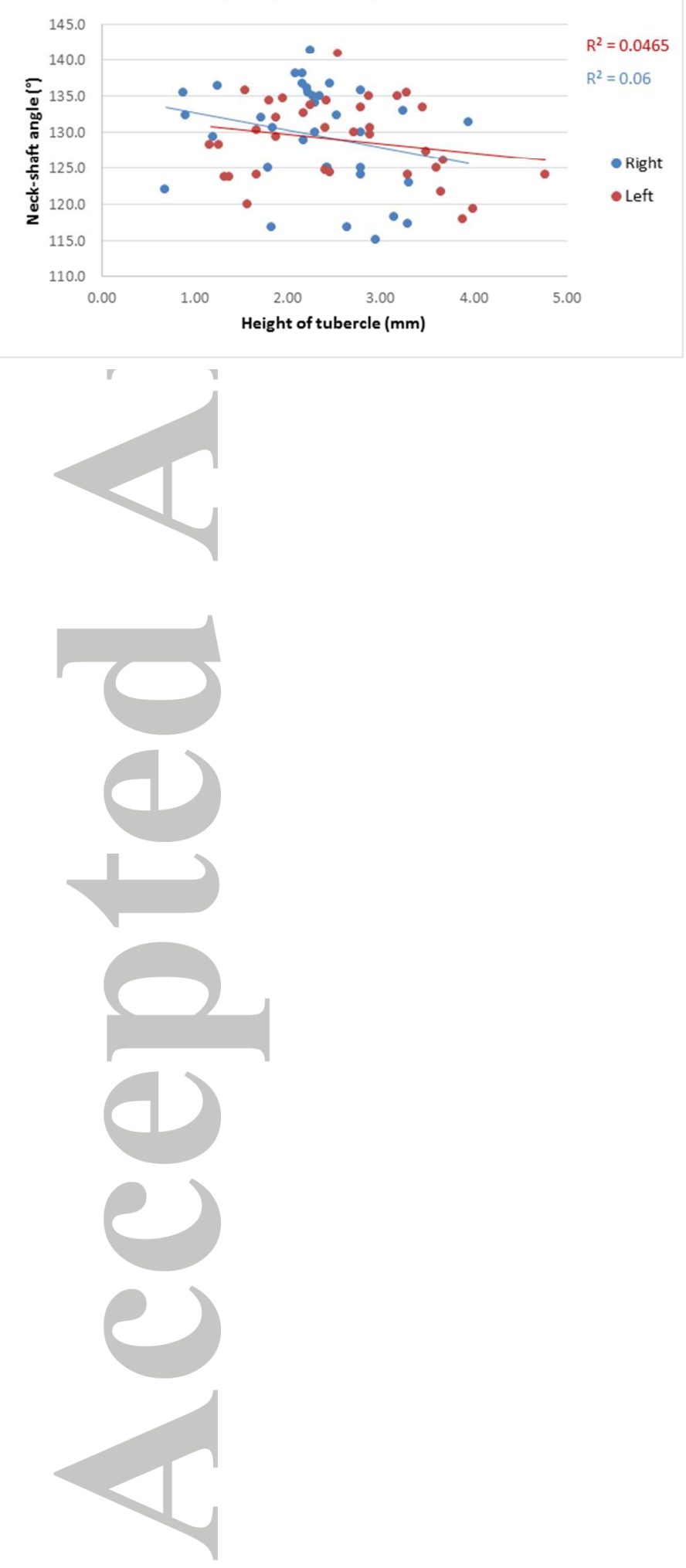

B Neck-shaft angle against height of tubercle (Females)

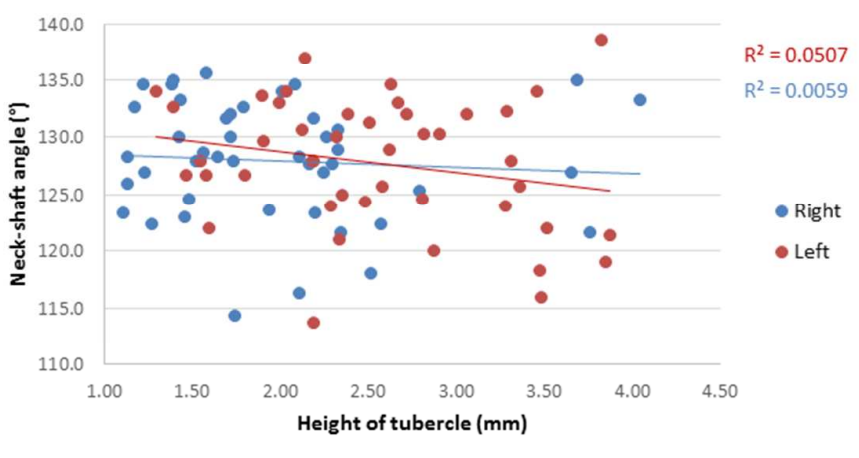

John Wiley and Sons, Inc.

This article is protected by copyright. All rights reserved. 